\title{
Drug Use amongst South African Youths: Reasons and Solutions
}

\author{
Andrew E. van Zyl \\ Department of Educational Leadership and Management, \\ College of Education, University of South Africa \\ E-mail:vzylae@unisa.ac.za
}

Doi:10.5901/mjss.2013.v4n14p581

\begin{abstract}
A literature study of the reasons for drug use amongst South African youths revealed that they are presented in a fragmented manner and not in a holistic way which would facilitate an integrated understanding of this social ill. This article places the key reasons for drug use amongst South African youths, namely the vulnerability of youths, peer pressure, inadequate role modelling by parents and significant others, community tolerance, availability of drugs, underactualisation of metaphysical values, poverty and unemployment, violence and national forces within Bronfenbrenner's ecological system to address this shortcoming. The etiology of drug use amongst South African youths, considered in an integrated perspective, would result in a better understanding thereof and could serve as a permanent basis for addressing the problem of drug use amongst South African youths at any particular period of time. Recommendations based on an integrated perspective of the etiology of this problem are also provided.
\end{abstract}

Keywords: Bronfenbrenner, etiology, adolescents, ecology

\section{Introduction}

The high prevalence of drug use amongst South African youths (Onya \& Flisher, 2008; Onya et al., 2012a) and its devastating consequences compel further research into its etiology in order to provide more effective measures to combat this social ill. Although no comprehensive national survey of drug use exists in South Africa (Brook et al., 2006), this social ill has been reported widely (Madi \& Matla, 2003; Morojele et al., in Parrry 1998; Townsend et al., 2007). The consequences of drug use amongst South African youths include irresponsible sex behaviour with its accompanying risk of contracting HIV (Plüddemann, et al., 2008), the reduced chances of obtaining employment as a result of school dropout (Chalton in Townsend et al., 2007; Plüddemann et al., 2010; Townsend et al., 2004) and increased violence and poverty (Congress of South African Trade Unions, 2011; Mncube and Harber, 2013; Sempi, 2007).

Although a literature study of drug use by South African youths provides many reasons for this phenomenon, they are very often discussed in a fragmentary fashion and not viewed in their interrelatedness within a broad sociological structure. The reasons for drug use amongst youths provided in this paper, namely the vulnerability of youths (Flisher et al., 2002; Mohasoa, 2010; Rocha-Silva, 1997; Stacey in Parry \& Bennetts, 1998; Ziervogel et al., 1997-1998), peer pressure (Ghuman et al., 2012; Hoberg, 1993; Hoberg, 2003; Ladikos et al., 2003; Mohasoa \& Fourie, 2012; Neser et al., 2001; Rocha-Silva et al., 1996; Parry et al., 2004), inadequate role modelling by parents and significant others (Amoateng et al., 2006; Brook et al., 2005; Brook et al., 2006; Meghdadpour et al., 2012; Morojele, et al., 2006), community tolerance (King et al., 2003; Morejele et al., 2006; Onya et al., 2012b; Parry et al., 2004), the availability of drugs (Mohasoa, 2010; Morejele et al., 2006 Neser et al., 2001; Parry \& Bennetts, 1998), the underactualisation of metaphysical values (Gana, 2004; Hamdulay \& Mash, 2011; Meghdadpour, 2012; Parry et al., 2004), poverty and unemployment (Kadalie \& Thomas, 2013:9; Kalichman et al., 2006; Parry et al., 2006), violence (Brook et al., 2006; Mncube and Harber, 2013) and comprehensive national forces (Brook et al., 2006), are therefore not adequately placed within a comprehensive theoretical framework that could serve as a basis for directives to combat this problem. The literature nevertheless shows a growing concern for the need to view the etiology of drug use amongst youths holistically (Florence \& Koch, 2011; Meghdadpour et al., 2012; Morojele et al., 2002; Pretorius et al., 2003). This article makes a contribution by showing that the interrogation of the reasons for the problem within a broad social context which allows for understanding them in their interrelatedness contributes towards its solution. Not only would it result in improved strategies to combat drug use among South African youths, it would also combat related problems such as violence (Mncube \& Harber, 2013) and poverty (Kalichman et al., 2006) and would therefore impact positively on South African 
youths' physical and mental wellbeing.

This article will present a brief overview of Bronfenbrenner's ecological model which will be used as a theoretical framework for positioning and interpreting the reasons for drug use amongst South African youths to accentuate the necessity of an integrated strategy to address this issue. This article should therefore be viewed as a synthesis paper based on a literature study of multiple sources related to the selected topic, geared towards establishing a logical entirety (Henning, 2011). Finally this paper provides recommendations based on an integrated approach to combat drug use amongst South African youths.

\section{Bronfenbrenner's Ecological Model}

Bronfenbrenner's ecological model, which serves as theoretical framework to interpret the reasons for drug use by South African youths, implies that a developing individual's environment encircles him/her like "a set of nested structures, each inside the other like a set of Russian dolls" (Bronfenbrenner \& Morris, 2007, p. 814). The sphere closest to the individual at the centre is called the microsystem. The microsystem, in turn, is surrounded by the exo- and macrosystems respectively.

The microsystem represents the individual's immediate environment. Bronfenbrenner (1993, p. 39) describes it as

"a pattern of activities, social roles, and interpersonal relations experienced by the developing person in a given face-toface setting with particular physical, social, and symbolic features that invite, permit, or inhibit engagement in sustained, progressively more complex interaction with, and activity in, the immediate environment."

The components of the microsystem would imply the family, school, and peer group. It could also include specific individuals, such as a particular teacher, who are closely associated with the individual at the centre. The linkages and processes between two or more components in the microsystem comprise the so-called mesosystem (Bronfenbrenner, 1993). The exosystem, the sphere which encloses the microsystem, is further removed from the individual, but nevertheless affects him/her indirectly. Components of the exosystem, which relates to the community, could be parents' workplaces, family friends and neighbours (Bronfenbrenner, 1993), as well as health care centres, mass media, friends of the family, welfare centres and parents other than those of the individual (Swart \& Pettipher, 2005).

The macrosystem, the sphere which frames the exosystem, is the system furthest removed from the individual and affects the individual at the centre via the exosystem. Bronfenbrenner (1993, p.40) refers to this system as the "societal blueprint for a particular culture or subculture", and the macrosystem's components could therefore include ideologies, economics, social values and politics (Swart \& Pettipher, 2005).

Apart from the micro- exo- and macrosystem which surrounds the individual at the centre of Bronfenbrenner's ecological model, Bronfenbrenner also distinguished a so-called chronosystem which does not resemble a system surrounding the individual. Rather, "[a] chronosystem encompasses change or consistency over time" (Bronfenbrenner, 1993, p. 40), either in terms of the individual at the centre or the individual's environment. For the peurposes of this paper, the chronosystem would entail, as shall be shown, the change from childhood to adulthood (the period of adolescence) as well as the current period of change in South African society.

\section{Reasons for Drug Use by South African Youths}

Key reasons for drug use by South African youths in terms of Bronfenbrenner's ecological model will be presented in this section before interpreting their interrelatedness and presenting future recommendations. The youth at the centre of Bronfenbrenner's ecological model serves as starting point of this discussion.

\subsection{Vulnerability to drug use experienced by the youth at the centre of Bronfenbrenner's ecological model}

The concept of youth implies "a period of transition from the dependence of childhood to adulthood's independence and awareness of interdependence" (UNESCO, 1995-2012). The youthful individual at the centre of Bronfenbrenner's ecological model would refer to a young person during the period that qualifies him/her for exiting compulsory education and being employed. It would therefore refer to adolescents (youths between the ages of 11 to 13 years and 18 to 20 years) (Mosby's Medical Dictionary, 2009) who are vulnerable to drug use since they find themselves in a phase of considerable experimentation (Flisher et al., 2002).

Youths' chances of succumbing to drug use would increase should feelings of physical and psychological 
discomfort be experienced. Interview responses obtained by Rocha-Silva (1997) showed that youths use drugs to gain confidence in dealing with people A report by Mohasoa (2010, p. 84) states that "[most] of the recipients [recorded] stress as the cause for the use of substances" since "they [were] overwhelmed by the challenges of their own lives, their families, and the societies in which they live". The same study revealed that drug users who use solvents attributed this behaviour to the cold in winter. Stacey (in Parry \& Bennetts, 1998, p. 80) reports that young people attributed their alcohol and drug abuse to their perception of "being people in desperate situations using substances to meliorate their lives".

Boredom as a reason for drug use experienced by youths was revealed by Ziervogel et al. (1997-1998) and Stacey (in Parry, 1998), though a study by Wegner et al. (2006) did not show this relation. Another study by Wegner et al. (2008), however, did show a relation between boredom and school dropout. School dropout would cause difficulty in obtaining a job, and increased stress brought about by dropout would increase the chances of drug use. Literature concerning boredom amongst South African youths, however, remains scarce (Wegner \& Flisher, 2009).

\subsection{Reasons related to the the microsystem}

Key reasons for drug use by youths which emerged from a scrutiny of relevant literature that can be related to the microsphere are peer pressure and inadequate role modelling by parents and significant others.

\subsubsection{Peer pressure}

Both qualitative and quantitative research shows the significance of peer pressure as a key reason for drug use amongst South African youths. In this regard, it was found that youths' social acceptance by their peers are highly valued (RochaSilva et al., 1996). Yielding to group pressure to use drugs was also indicated by Hoberg (1993; 2003) who found that peers had great respect for the opinions of members of their peer groups. Interviewees stated that they would rather discuss their problems with somebody of their age group than with parents, teachers, the school psychologist or a medical doctor. Research conducted by Mohasoa and Fourie (2012) revealed that peers were considered the primary providers of support and that they composed the most prominent factor causing drug use amongst youths. Peer pressure as reason for drug use is also implied by a study undertaken by Parry et al. (2004) who found, with an 88,9\% accuracy, that youths who reported life-time drunkenness were significantly likely to have friends who use alcohol. According to Ghuman et al. (2012), adolescents were 3,6 times more likely to have used alcohol and to have been involved in binge drinking in the preceding month if they had friends who used alcohol. Their study showed that adolescents were offered their first drink by friends rather than others. Research undertaken by Neser et al. (2001) amongst 2281 grades 7, 10 and 11 learners in the $\mathrm{N}-3$ district schools in Pretoria revealed the tremendous effect of peer pressure on drug use: $91,4 \%$ of white learners, $77,5 \%$ of Indian learners, $59,1 \%$ of black learners and $59 \%$ of white learners who smoked tobacco attributed this behaviour to their friends' examples. Similar results were reported by Ladikos et al. (2003). A study conducted by Parry et al. (2004) showed that adolescents who had reported life-time drunkenness were found to be significantly likely, with an $88,9 \%$ accuracy, to have friends who use alcohol (Parry et al., 2004).

\subsubsection{Inadequate role modelling by parents and significant others}

A study undertaken by Ghuman et al. (2012) revealed that adolescents consider their parents and guardians as being the most influential people in their lives. This view concurs with their finding that adolescents are 1,9 and 1,5 times more likely to have used alcohol and binged on drinking respectively if they have often observed their fathers being drunk.

The importance of the influence of parents who use drugs on their adolescent children was also illustrated by Brook et al. (2006). They found that mothers' use of drugs in terms of smoking tobacco and marijuana and consuming alcohol, and fathers' use of alcohol and marijuana bore a significant relation to the frequency of their adolescent children's use of illegal drugs.

Morojele et al. (2006) found that the mimicking of parental behaviour was partly responsible for drug use amongst peers. In this regard, Brook et al. $(2005$, p. 214) report that the"[m]odeling of smoking behaviour by friends, significant others, and siblings ... constitute important categories of social-influence variables".

Concerning the influence of parental behaviour on their children, Amoateng et al. (2006) report that parental behaviour of control, anchored in parents' knowledge of their children's activities and limit-setting, is significantly predictive of lower levels of alcohol and tobacco use. They also indicated that overt but not covert marital hostility was 
associated with the use of the mentioned drugs. An extensive study conducted by Meghdadpour et al. (2012) among 11 904 South African youths between 15 to 24 years of age showed that family supervision was significant in curbing drug use: family supervision accounted for a $23 \%$ reduced chance of male youths having been drunk and a $38 \%$ lower chance of having used illegal drugs.

\subsection{Reasons related to the the exosystem}

This section provides information regarding the following reasons for drug use amongst South African youths that emerged from the literature study: community tolerance, availability of drugs, underactualisation of metaphysical values, povery and unemployment, and violence.

\subsubsection{Community tolerance}

Research undertaken by King et al. (2003, p. 120) showed that

"the impact of sociological forces on youths' smoking behaviour may be mediated through antisocial adult behaviour, subjective adult norms, and community affirmation."

'Antisocial behaviour', in this context, refers to adults' use or selling of illegal drugs and their having been confronted by the police in terms of illegal drugs, whilst the concept 'subjective adult norms' refers to adults condoning the use of marijuana, and agreeing to their adolescent children's consumption of alcohol and smoking of cigarettes. Onya et al. (2012b) found that community antisocial behaviour, run down communities and community affirmation could be significantly linked to secondary school students' use of home-brewed alcohol in the rural area of Mankweng in the Limpopo Province. However, affirmation expressed as appreciation and recognition of work well done, revealed a significant relation to adolescents' abstaining from drinking home-brewed alcohol.

A significant relation between drug use and community tolerance was shown by Parry et al. (2004) who indicated correlations between adolescents who had been drunk and communities where alcohol could be obtained easily and where police failed to respond to youths' use of alcohol. A study undertaken by Morejele et al. (2006) indicated that Xhosa and Afrikaans-speaking community members in Cape Town blamed community tolerance for the widespread selling and use of drugs in their neighbourhoods.

\subsubsection{Availability}

The study by Morejele et al. (2006) revealed that adolescents considered the accessibility of drugs as a reason for drug abuse amongst their age group. It was shown by Tibbs and Parry (in Parry \& Bennetts, 1998) that secondary school learners, aged 14 to 16 years, could obtain their liquor directly from legal public outlets and shebeens. Towards the end of the $20^{\text {th }}$ century only one tenth of liquor outlets were licensed and approximately 190000 shebeens were in operation (Parry \& Bennetts, 1998).

Easy access to drugs was also reported by Mohasoa (2010). She showed that the majority of male adolescents involved in her study, undertaken in the rural areas of Zeerust in North West Province, were of opinion that they could acquire drugs from local shops, taverns, and butcheries. A study by Neser et al. (2001) indicated that a third of 2281 secondary school learners in secondary schools in the N-3 district of Pretoria were of the opinion that dagga could be obtained within an hour whilst a quarter believed that LSD, ecstasy, cocaine and heroin could be bought within a day. Parry and Bennetts (1998) consider the availability of alcohol as being related to the view that drinking represents adulthood as expressed in alcohol advertisements.

\subsubsection{Underactualisation of metaphysical values}

Hamdulay and Mash (2011), Gana (2004) and Meghdadpour et al. (2012) found that faith in a religion is a restricting factor in terms of drug use by adolescents. The study conducted by Meghdadpour et al. (2012) showed that males between the ages of 15 and 24 who attended faith services, at least on a weekly basis, had a reduced chance of $50 \%$ to $60 \%$ in terms of ever having consumed alcohol, having been drunk in the previous month, and having ever used illegal drugs. Parry et al. (2004) found that the odds of having been drunk show a dramatic decrease if adolescents attended religious services. 
The underactualisation of metaphysical values as reason for drug use cannot be placed only in the exosystem since the home in the microsystem may also contribute towards the neglect of metaphysical values.

\subsubsection{Poverty and unemployment}

According to Kalichman et al. (2006, p. 1647), poverty is an indicator of substance use since the latter "may serve as a means of coping with the daily pressure of poverty". This view is concurrent with that of Parry et al. $(2005$, p. 91) who found that indicators of alcohol problems showed a significant association "with lower socioeconomic status, no school education and being older than 25 years of age". The role that unemployment plays in drug use should, according to Kadalie and Thomas (2013), be viewed in terms of its relation to morale loss and social degradation resulting from the poverty that unemployment causes. The prevailing high unemployment rate of $51 \%$ among 15 to 24 year olds, as reported at the end of January 2011 (IOL News, 2011; SAIRR, 2011) provides an explaination for the widely experienced poverty in South Africa. Drug use by adults, aimed at escaping despair, could influence adolescents who pursue adulthood to display similar behaviour which, in turn, could negatively influence their peers, causing an increased reduction in chances of obtaining employment.

The relation between drug use and poverty was accentuated thus by COSATU's general secretary, Mr Zwelenzima Vavi, during his address at the Second Biennial Substance Abuse Summit on 16 March 2011 (Congress of South African Trade Unions, 2011):

[1]n short, it is poverty and unemployment and the lack of any recreational facilities that leave young people with a feeling of hopelessness and worthlessness. If they see no prospect of ever getting a decent job and enough income to live a normal live, seeking oblivion through drugs and/or alcohol becomes a tempting escape route.

\subsubsection{Violence}

Literature reveals reciprocity between violence and drug use by youths (Brook et al., 2006). An extensive research project headed by Mncube and Harber (2013) at secondary schools in Kwazulu-Natal, North West Province, Western Cape, Limpopo Province, Gauteng and Mpumalanga revealed that respondents from these provinces considered drug use to be a key reason for violence, which manifested, inter alia, in physical violence geared towards educators and the damaging of school property. The interplay between the use of drugs and violence would mean that the causes of violence disclosed in the mentioned study by Mncube and Harber (2013), including challenged communities, gangsterism and racial tensions, would also relate to drug use since each of them has the potential to increase the stress experienced by the youth at the centre of Bronfenbrenner's ecological model, thereby intensifying his/her vulnerability to drugs. Brook et al. (2006) hypothesize that high levels of environmental stress would relate to increased substance use by adolescents. In this regard they mention current stressors which occur in society, namely prevailing violence and crime, high rates of unemployment, technological changes and the AIDS epidemic.

\subsection{Reasons related to the the macrosystem}

High levels of environmental stress in the exosphere would influence drug use by youths (Brook et al., 2006), either directly or indirectly. Whether stressors constitute direct causes for drug use amongst youths and/or bring about the direct causes in the microsystem to come into play and feed on each other, they should not be viewed as being unrelated to aspects in the macrosystem.

South Africa's new political dispensation heralded a new and just value system which has been opening doors for previously disadvantaged South African youths. Yet, this liberation, because of its enormity, could influence impressionable adolescents to claim adulthood more ardently and to follow improper "adult" behaviour such as drinking and smoking. General values which are currently emphasised, namely those of being in possession of working skills, being competitive and insisting on one's right could also affect drug use amongst South African youths. In themselves these values are admirable, but if youths become obsessive in their pursuit of them, they could cause increased stress which would make them more vulnerable to drug use.

Another crucial aspect pertaining to drug use by youths concerns the difficulty experienced by the government to create sufficient jobs to uplift financially challenged communities in the exosphere. Adeqaute job opportunities would impact positively on the eradication of poverty and decrease improper role modelling by parents and significant others who use drugs to escape from their despair. It could be said that poverty would directly and/or indirectly have a negative 
effect on the mental wellbeing of youths finding themselves at the centre of Bronfenbrenner's ecological model, thereby making them more vulnerable to seek relief in the use of drugs.

\section{Relationships between Reasons for Drug Use in Bronfenbrenner's Ecological Model}

It was mentioned earlier that the mesosystem refers to the interaction between components in the microsystem. Two components, representing the key reasons for drug use amongst South African youths, namely peer pressure and inadequate role modelling by parents and significant others, indeed show close cooperation since they reinforce each other. The school can also be viewed as an interrelated component in the microsphere which can promote the use of drugs since it serves as an obligatory meeting place for members of peer groups. It stands to reason that the link between the reasons for drug use in the microsphere needs to be broken in addressing drug use amongst South African youths.

As shown, the reasons for drug use amongst South African youths in the exosphere would impact on youths directly and/or indirectly via components of the microsystem. As is the case with reasons for drug use by youths in the microsphere, reasons in the exosphere may also show an interconnectedness. No single explanation in this regard would suffice, but it could be said, for example, that the reasons of poverty and unemployment and related violence would influence the availability and tolerance of drugs "favourably" since they would increase the perceived need for drugs. Another reason for drug use in the exosystem, namely the underactualisation of metaphysical values, would complement easy access to drugs and communities' tolerance thereof.

It was pointed out that the use of drugs by parents and significant others in the microssystem could encourage drug use by youths and their peers as a consequence of poverty and unemployment in the exosphere which, in turn, can be related to government's difficulty in the macrosphere to effectively address this reason for drug use amongst youths. General values in the macrosystem, such as having to be competitive and assertive, would also support drug tolerance and easy access to drugs since they could increase stress which could cause experiences of needing sedation amongst youths. In essence it could be said that the reasons for drug use amongst youths constitute a web which comprises the micro-, exo- and macrosystem of Bronfenbrenner's ecological model.

\section{Addressing Drug Use amongst South African Youths}

Since the microsphere has an intense and direct influence on an individual, it should be emphasised in combating drug use, even though optimum change could hardly take place without complementary changes in the exo- and macrospheres. Schools would provide a logical starting point for combatting drug use amongst South African youths since they could initiate a change in peer pressure and parent behaviour, thereby decreasing the chances of drug use. Schools can effect change since it is in a constant position of having teachers and learners in its population who could take a stand against drug use.

Hoberg (1993) considers exemplary peer leaders as the most important measure to combat drug use amongst youths. In this regard, school managers should promote the election of model learners to the Representative Council of Learners. Once elected, they should be trained and utilised to optimise their positive influence on peers. Exemplary learner leaders who have achieved in areas in which fellow learners show interest, such as sport, singing and dancing, could exercise a positive influence either through direct contact with peers groups or by means of their known anti-drug stance. Cooperation between school managers and the Representative Council of Learners could involve anti-drug campaigns, which could include presentations by knowledgeable people such as medical practitioners and rehabilitated drug users.

School governing bodies should accentuate parent involvement in combating drug use so that parents and peers, the two most important influences on youths, convey the same anti-drug message. Appropriate parent involvement initiatives, including parent training programmes in terms of drug use could be developed by selected parents, learners, teachers and relevant organisations and key figures in the community, so that a network which counteracts drug use in the micro- and exosphere is established. Parent involvement should therefore be approached in terms of Epstein's theory of overlapping spheres (Epstein, 2011) which emphasises cooperation between schools, parents and communities. To address the underactualisation of metaphysical values, the involvement of religious groups and spiritual leaders could be sharpened.

In addition to aspects pertaining to the exosphere mentioned thus far, the South African Police Services should intensify its focus on the identification and prosecution of drug pushers, illegal suppliers of alcohol and tobacco, as well 
as legal providers of alcohol and tobacco who transgress in terms of prescribed trading hours and the minimum age of their clientele. Good relationships between employers of the South African Police Services and the public should be established to increase reporting of drug pushing and illegal drug use by parents, teachers and other members of the community.

Another issue in the exosphere that should be addressed is the alleviation of boredom amongst South African youths in communities of low socio-economic status. The possibility of establishing groups catering for the interests of youths, such as chess playing, reading, dancing and ecological recovery and sustainment, could be investigated by schools, neighbourhood interest groups and local authorities. Schools and other facilities known to parents could play a meaningful role in the provision of venues for activities of leisure. Modes of exploiting mass media in making the dangers of drug abuse known, such as television programmes aimed at the youth, could be interrogated to counteract drug use by bored youths.

In the macrosystem every effort by the government is needed to reach its target of having created 11 million jobs by 2030 and increasing the economic growth threefold (South African Government Information, 2013; OECD, 2013). Its most powerful contribution in combating drug use by South Africans would be the eradication of poverty, thereby empowering parents, their adolescent children and other members of the community to regain hope for a sustainable future. The government should also ensure that anti-drug initiatives in the exosphere are given its dedicated support.

It has to be borne in mind that the theoretical interpretation of reasons for drug use amongst South African youths discussed in this paper, provide a broad and generic framework of the problem which should be particularised in terms of different social contexts. Provision should be made for varying degrees of addressing particular reasons for drug use amongst South African youths within specific communities.

\section{Conclusion}

This paper has shown that the reasons of drug use amongst South African youths identified by means of a literature study are complex if they are viewed in their interrelatedness in terms of Bronfenbrenner's micro-, exo- and macrosystems. To combat drug use amongst youths, an integrated strategy involving these three systems should therefore be employed to break the etiological chain of drug use amongst South African youths. Such a strategy would be valid for any particular period of time. Of particular importance is the penetration of the microsphere as its influence on youths is significant and direct. The problem could, however, only be addressed optimally by a total onslaught involving the integrated action in the micro-, exo-, and macrosystem.

\section{References}

Amoateng, A.Y., Barber, B.K. \& Erickson, L.D. (2006). Family predictors of adolescent substance use: the case of high school students in the Cape Metropolitan Area, Cape Town, South Africa. Journal of Child and Adolescent Mental Health, 18(1): 7-15.

Bronfenbrenner, U. (1993). Ecological models of human development. In Gauvain, M. \& Cole, M. (Eds.). Readings on the development of children, $2^{\text {nd }}$ edition. New York: Freeman, pp. 37-43.

Bronfenbrenner, U. \& Morris, P.A. (2007). Wiley Online Library. Handbook of Child Psychology. http://scholar.google.co.za/scholar?q =related:Pv1tPRY4HyAJ:scholar.google.com (March 14, 2013)

Brook, J.S., Morojele, N.K., Brook, D.W. \& Rosen, Z. (2005). Predictors of cigarette use among South African adolescents. International Journal of Behavioral Medicine, 12 (4): 207-217.

Brook, S., Morojele, N.K., Pahl, K. \& Brook, D.W. (2006). Predictors of drug use among South African adolescents. Journal of Adolescent Health, 38(1): 26-34.

Congress of South African Trade Unions. (2011). Address by the general secretary at the Second Biennial Substance Abuse Summit, Durban. [Online] Available: http://www.polity.org.za/article/cosatu-vavi-address-by-the-general-secretary (October 15, 2012)

Dada, S., Plüddemann, A., Williams, Y., Parry, C., Bhana, A., Vawda, M., Pereira, T. \& Kitshoff, P.E. (2012). Monitoring alcohol and drug abuse treatment admissions in South Africa. August 2012. Phase 31, July to December 2011. [Online] Available: http://www.sahealthinfo.org/admodule/sacendu/SACENDUFullReport11b.pdf (Feb 12, 2013)

Epstein, J.L. (2011). School, family and community partnerships. Preparing educators and improving schools. Boulders, CO: Westview Press.

Flisher, A.J., Parry, C.D.H., Muller, M. \& Lombard, C. (2002). Stages of substance use among adolescents in Cape Town, South Africa. Journal of Substance Use, 7(3): 162-167.

Florence, M. \& Koch, E. (2011). The difference between adolescents and non-users of addictive substances in a low socio-economic status community: contextual factors from the perspective of subjective wellbeing. South African Journal of Psychology, 41(4): 477-487.

Gana, T.C. (2004). The influence of peer, community and religion on adolescent substance use in the Cape Metropolitan Area. 
Unpublished MA mini-thesis. Cape Town: University of the Western Cape.

Ghuman, S., Meyer-Weitz, A.\& Knight, S. (2012). Prevalence patterns and predictors of alcohol use and abuse among secondary school students in southern KwaZulu-Natal, South Africa: demographic factors and the influence of parents and peers. South African Family Practice, 54(2): 132-138.

Hamdulay, A.K. \& Mash, R. (2011). The prevalence of substance use and its associations amongst students attending high school in Mitchell's Plain, Cape Town. South African Family Practice, 53(1): 83-90.

Henning, T.B. (2011). Literature review; synthesizing multiple sources. Handout paper updated February, 2011. Indiana: School of Liberal Arts, Indiana University Writing Centre. [Online] Available: www.iupui.educ uwe (June 11, 2013)

Hoberg, S.M. (1993). Verband tussen portuurgroepdruk en dwelmverslawing by skoolgaande adolessente. South African Journal of Education 13(4): 159-165.

Hoberg, S.M. 2003. The crisis generation: peer influence on adolescent substance abuse. Educare, 32(1\&2): 240-260.

IOL Independent Online News. (2011). [Online] Half of South Africa's youth are unemployed. Available at: http://www.iol.co.za/news Isouth-africa/half-of-sa-s-youth-are-unemployed (May 29, 2013)

Kadalie R. \& Thomas, M. 2013. Unemployment plays big role in substance abuse. Alcohol, drug use in SA twice the global average. Citizen, April, 26 (1982). [Online] Available at: http://www.citizen.co.za (June 11, 2013)

Kalichman, S.C., Simbayi, L.C., Kagee, A., Toefy, Y., Jooste S., Cain, D. \& Cherry, C. (2006). Associations of poverty, substance use, and HIV transmission risk behaviours in three South African communities. Social Science \& Medicine, 62: 1641-1649.

King, G., Flisher, A.J., Mallett, R., Graham, J. \& Lombard, C. (2003). Smoking in Cape Town: community influences on adolescent tobacco use. Preventative Medicine, 36(1):114-123.

Ladikos, A., Prinsloo, J. \& Neser, J. (2003). An opinion survey on teenage substance abuse indicators: an application of the Chaid analysis. Acta Criminologica, 16(5):161-174.

Madi, S.N. \& Matla, M.P. 2003. Illicit drug use, cigarette smoking and alcohol drinking behaviour among a sample of high school adolescents in the Pietersburg area of the Northern Province, South Africa. Journal of Adolescence, 121-136.

Meghdadpour, S., Curtis, S., Pettifor, A. \& MacPhail, C. (2012). Factors associated with substance use among orphaned and nonorphaned youth in South Africa. Journal of Adolescence, 35(5):1329-1340.

Mncube, V. \& Harber, C. (2013). The dynamics of violence in South African schools. Pretoria: University of South Africa.

Mohasoa, I.P. (2010). Substance abuse among male adolescents. Unpublished MA dissertation. Pretoria: University of South Africa.

Morojele, N.K., Brook, J.S. \& Kachieng'A, M.A. 2006. Perceptions of sexual risk behaviours and substance abuse among adolescents in South Africa: a qualitative investigation. Aids Care: Psychological and Socio-Medical Aspects of Aids/HIV, 18(3):215-219.

Morojele, N.K., Flisher, A.J., Muller, M., Ziervogel, C.F., Reddy, P., Lombard, C.J., Flisher, A.J. \& Ziervogel, C.F. (2002). Measurement of risk and protective factors for drug use and anti-social behaviour among high school students in South Africa. Journal of Drug Education, 32 (1):25-39.

Mosby's Medical Dictionary, (2009). The Free Dictionary by Farlex. [Online] Available: http://medical-dictionary.thefreedictionary.com ladolescence (June 20, 2013)

Neser, J,J., Ovens, M., Victor-Zietsman, M.M.J. \& Ladikos, A. (2001). Views of learners on drugs and related matters: preliminary findings. Crime research in South Africa, 3(3): 1-14.

OECD (Organisation for Economic Co-operation and Development). (2013). Economic Surveys: South Africa 2013. [Online] Available: http://dx.doi.org/10.178_surveys-zaf-2013-en (June 4, 2013)

Onya, H.E. \& Flisher, A.J. (2008). Prevalence of substance use among rural high school students in Limpopo Province, South Arica. African Journal of Drug and Alcohol Studies, 7(2):71-79.

Onya, H., Tessera, A., Myers, B. \& Flisher, A. (2012a). Adolescent alcohol use in rural South African high schools. African Journal of Psychiatry, 15 (Spring):352-357.

Onya, H., Tessera, A., Myers, B. \& Flisher, A. (2012b). Community influences on adolescents' use of home-brewed alcohol in rural South Africa. BMC Public Health. http://www.biomedcentral.com/1471-2458/12/642 (Retrieved June 13, 2013)

Parry, C.D.H. (1998). Substance abuse in South Africa: Country report focussing on young persons.Tygerberg: Medical Research Council.

Parry, C.D.H. \&, Bennetts, A.L. (1998). Alcohol policy and public health in South Africa. Cape Town: Oxford: University Press.

Parry, C.D.H., Morojele, N.K., Saban, A. \& Flisher, A.J. (2004). Brief report: Social and neighbourhood correlates of adolescent drunkenness: a pilot study in Cape Town, South Africa. Journal of Adolescence, 27(3): 369-374.

Parry, C.D.H., Plüddemann, A., Steyn, K., Bradshaw, D., Norman, R. \& Laubscher, R. (2005). Alcohol use in South Africa: Findings from the first demographic and health survey (1998). Journal of Studies on Alcohol and Drugs, 66(1): 91-97.

Plüddemann, A., Flisher, A.J., Matthews, C., Carney, T. \& Lombard, C. (2008). Adolescent methamphetamine use and sexual risk behaviour in secondary school students in Cape Town, South Africa. Drug and Alcohol Review, 27: 687-692.

Plüddemann, A., Flisher, A.J., McKetin, R., Parry, C.D. \& Lombard C.J. (2010). A prospective study of metaphetamine use as a predictor of high school non-attendance in Cape Town, South Africa. PubMedCentral Online Available: http://www.ncbi.nlm.nih.gov/pmc/articles/PMC2984579/?tool=pubmed (December 10, 2012)

Pretorius, C., Van den Berg, H.C. \& Louw, D.A. (2003). Psychosocial predictors of substance abuse among adolescents. Acta Criminologica, 16(4):1-11.

Rocha-Silva, L. (1997). The nature and extent of drug use and the prevalence of related problems in the RSA: The initiation and sustainment of national surveillance. Pretoria: HSRC Publishers. 
Rocha-Silva, L., De Miranda, S. \& Erasmus, R. (1996). Alcohol, tobacco and other drug use among black youth. Pretoria: HSRC Publishers.

SAIRR (South African Institute of Race Relations). (2011). Press Release, January 31. [Online] Available: www.sairr.org.za/media/media-release (February 5, 2013)

Sempi, M.D. (2007). Relationship between adolescent substance abuse and violence in Batho policing area. Unpublished MA dissertation. Pretoria: Tshwane University of Technology.

South African Government Information. (2013). State of the Nation Address by His Excellency Jacob G Zuma, President of the Republic of South Africa on the Occasion of the Joint Sitting of Parliament Cape Town. February 14, 2013. http://www.info.gov.za /speech/DynamicAction/pageid (Retrieved June 15, 2013)

Swart, E. \& Pettipher, R. (2005). A framework for understanding inclusion. In: Landsberg, E., Kruger, D. \& Nel, N. (Eds.). 2005. Adressing barriers to learning. Pretoria: Van Schaik, pp. 3-22.

Townsend, L., Flisher A.J. \& King, G. (2007). A systematic review of the relationship between high school dropouts and substance use. Clinical Child and Family Psychology, 10(4): 295-317.

Townsend, L., Flisher, A.J., Chikbovu, P. \& Lombard, C. (2004). Relation between substance use and high school dropout in Cape Town, South Africa. Paper delivered at the American Public Health Association's 132nd annual meeting. Washington, DC, November 6-10. [Online]Available: https://apha.confex.com/apha/132am/techprogram/paper90681.htm (June 6, 2013)

UNESCO (United Nation's Educational and Scientific Cultural Organization). 1995-2012. Social and Human Sciences. What do we mean by "youth"? [Online] Available: Unesco.org/news/en/social-and-human-sciences/themes/youth/youth-definition/ (June 11, 2013)

Wegner, L. \& Flisher, A.J. (2009). Leisure boredom and adolescent risk behaviour: a systematic literature review. Journal of Child and Adolescent Health, 21(1):10-28.

Wegner, L., Flisher, A.J., Chibokvu, P., Lombard, C. \& King, G. (2008). Leisure boredom and high school dropout in Cape Town, South Africa. Journal of Adolescence, 31(3): 421-431.

Ziervogel, C.F., Ahmed, N., Flisher, A.J. \& Robertson, B.A. (1997-1998). Alcohol misuse in South African male adolescents: a qualitative investigation. International Quarterly of Community Health Education, 17 (1): 25-41. 
